\section{Discussion}

It is generally accepted that in the "sudden death infancy syndrome" the infants have been healthy during life and they die because of some critical combination of environmental and intrinsic factors, either by a respiratory mechanism (Bergman et al., 1970; Shaw, 1970), a lethal cardiac arrythmia or conduction disturbance (James, 1968; Ferris, 1972), or a hypersensitivity reaction to antigens, at present unidentified but thought to be in cows' milk protein (Parish et al., 1960).

One of the major difficulties has been to relate the dramatic unexpected suddenness of death to the apparently minor changes seen at necropsy. A feature which is present at necropsy in most cases is intrathoracic, multiple petechial haemorrhages almost entirely confined to the thymus, the surface of the pleurae, and the epicardium-particularly in the atrioventricular groove. The possible aetiological importance of these haemorrhages was stressed by Bergman et al. (1970). Traditionally, petechial haemorrhages are attributed to asphyxial deaths, but as Teare and Knight (1971) pointed out such haemorrhages are commonly seen in cases where no asphyxia or suffocation has occurred, and they stressed that under no circumstances must the presence of such petechiae be interpreted as indicating an unnatural death. Because of a fear of incorrect interpretation of these petechial haemorrhages their significance in the sudden death in infancy syndrome has been minimized.

Lewis and Matheson (1910) experimentally produced heartblock by asphyxia and proved that it was hypoxia and not the accumulation of carbon dioxide that was responsible for the resultant dysrhythmias. Thung et al. (1962) as a result of both clinical and experimental evidence were able to show the importance of hypoxia as a cause of dysrhythmia. In a series of newborn infants who died of pulmonary insufficiency and patients who had been hypoxic before death it was found that the hypoxia was frequently associated with haemorrhages into the conducting system. Comparable haemorrhages with associated dysrhythmias were produced in experimental animals in a low oxygen atmosphere and it was concluded that these haemorrhages and the dysrhythmias were causally related. In a group of 10 out of 25 perinatal infant deaths similar conducting tissue haemorrhages were reported by Hoch-Ligeti and Diaz-Perez (1962). They considered these lesions to be significant factors in a failure to survive respiratory problems in the perinatal period.

The conducting system is one of the most heavily vascularized parts of the heart. Large thin wall venous sinuses can be easily seen and it is possible that hypoxia produces changes in the capillary walls, increasing permeability and thus predisposing to haemorrhage. Such haemorrhages may be further contributed to by a terminal congestive phase with a rise in venous pressure.

In the sudden death in infancy syndrome the problem in the past has been to rationalize the relatively trivial changes often reported in the lungs with the dramatic suddenness of death. Most of the current theories on the cause of death in these cases implicate respiratory distress either as a result of brochospasm associated with sensitivity to inhaled cows' milk protein (Camps, 1970) or to a respiratory infection (Bergman et al., 1970). It seems possible that, since such respiratory problems will be associated with varying degrees of hypoxia, fatal haemorrhages could occur in the conducting system by the mechanisms indicated. In all 11 cases reported here the haemorrhages were within recognizable conducting tissue structures and as such must be thought significant in the mechanism of death. It is possible that a predisposition to such haemorrhages may well account for a failure to survive in the sudden death in infancy syndrome and provide the important link between minimal observed pathological changes and sudden death.

I am indebted to Dr. W. A. Aherne for the provision of several cases, to Professor A. G. Heppleston for his continuing encouragement and advice in this work, and to Mr. J. Maclennan and Mr. A. E. Young for their technical and photographic expertise.

\section{References}

Bergman, A. B., Beckwith, J. B., and Ray, C. G. (1970). Sudden Infant Death Syndrome. Seattle, University of Washington Press.

Camps, F. E. (1970). British fournal of Hospital Medicine, 4, 779.

Camps, F. E., and Carpenter, R. G. (1972). Sudden and Unexpected Deaths in Infancy. Bristol, John Wright.

Ferris, J. A. J. (1972). Medicine, Science and the Law, 12, 173.

Gardner, P., Ferris, J. A. J., and Aherne, W. A. (1973). In preparation.

Hoch-Ligeti, C., and Diaz-Perez, R. (1962). American fournal of Obstetrics and Gynecology, 84, 804.

James, T. N. (1963). American Heart fournal, 66, 498

James, T. N. (1968). American fournal of Cardiology, 22, 479.

Lewis, T., and Matheson, G. C. (1910). Heart, 2, 47.

Parish, W. E., Barrett, A. M., Coombs, R. R. A., Gunter, M., and Camps, F. E. (1960). Lancet, 2, 1106

Shaw, E. B. (1970). American fournal of Diseases of Childhood, 119, 416. Teare, D., and Knight, T. (1971). Science fournal, January, p. 71.

Thung, N., et al. (1962). Fournal of Thoracic and Cardiovascular Surgery, 44,687 .

\title{
Automatic Transmission Vehicle Injuries
}

\section{MALCOLM FIDLER}

British Medical fournal, 1973, 2, 25-26

\section{Summary}

Four drivers sustained severe injuries when run down by their own automatic cars while adjusting the carburettor or throttle linkages. The transmission had been left in the "Drive" position and the engine was idling. This accident is easily avoidable.

Royal National Orthopaedic Hospital, London W1N 6AD

MALCOLM FIDLER, F.R.C.s., Orthopaedic Registrar (At present Senior Orthopaedic Registrar, Whittington Hospital, London N19 5NF)

\section{Introduction}

During recent years considerable interest has been focused on the injuries associated with road traffic accidents, their mechanism, methods of treatment, and means of prevention. The following four case reports describe injuries sustained by drivers run down by their own vehicles. In each case the car had automatic transmission, the injury was severe, and could easily have been avoided. This type of accident has not previously been described.

\section{Case Reports}

Case 1.-A man aged 66 was admitted to University College Hospital in June 1964. He had been adjusting the carburettor of his Mercedes-Benz motor car with the engine idling, and although the vehicle was stationary the automatic transmission was in the drive position. He increased the engine speed by moving the 
throttle linkage and the car surged forward crushing his left leg between the bumper and garage wall. He sustained a compound comminuted fracture of the left tibia and fibula. Subsequently he made a satisfactory recovery.

Case 2.-A 25-year-old woman was admitted to the Royal National Orthopaedic Hospital in December 1967. She had been adjusting the accelerator cable of her Vauxhall Cresta motor car. As the engine speed was increased the car accelerated forward, running her over. The transmission had inadvertently been left in the drive position. She had a transverse fracture of the mid shaft of the right femur, traumatic separation of the symphysis pubis, fracture of the left superior pubic ramus, fracture of the left ischiopubic junction, undisplaced fracture of the medial wall of the right acetabulum, and numerous superficial lacerations. The lacerations were sutured, the fractured femur was treated with skeletal traction and the diastasis of the pubic symphysis was reduced with a pelvic sling. Next day she developed cerebropulmonary fat emboli, became unconscious, and required tracheostomy and intermitten positive pressure respiration for 10 days. Thereafter she made a satisfactory recovery and was discharged on 2 April 1968. She was subsequently readmitted for the excision of a bony spur which formed in the adductor region as a result of myositis ossificans and again for cosmetic reconstruction of her tracheostomy scar which had become keloid. When seen in August 1969, the right leg was $1.5 \mathrm{~cm}$ short and she had a slight ache in the right hip, which had a full range of movement. She could walk as far as she wished.

Case 3.-A man aged 44 was admitted to University College Hospital in July 1970. He had been leaning over the front of his taxi adjusting the accelerator linkage with the engine idling. The automatic transmission was in the drive position. As he increased the engine speed the taxi moved forward and crushed his left leg against the bumper of another taxi. He sustained a severe compound fracture dislocation of the left knee. After 10 weeks in hospiral including open reduction of the fracture dislocation and skin grafting he continued mobilization as an outpatient. Five months after his injury he returned to driving an automatic taxi. One year after the injury his knee was pain-free but flexion was limited to $45^{\circ}$ and there was slight instability of the medial ligament.

Case 4.-A 57-year-old man was admitted to the Royal National Orthopaedic Hospital in August 1971. The idling speed of his
Austin 1300 car was too slow and he had been adjusting the slow running control of the carburettor. The automatic transmission was in the drive position. As he increased the idling speed the car surged forward crushing him against the garage wall. He sustained a posterior fracture dislocation of the right hip and superficial lacerations to both legs. The dislocation was reduced and after six weeks in traction he was mobilized. Subesquently he made satisfactory progress. One year after his injury he was walking with a slight limp. The hip was pain-free apart from an ache in the right buttock after walking one mile.

\section{Discussion}

Automatic transmission is becoming more popular each year and in 1971 it was fitted to $10 \%$ of motor cars produced by one large British manufacturer. Possibly as a result of rising charges, an increasing number of neople are doing minor adjustments to their own cars. When adjusting the carburettor or throttle linkage of a car with manual transmission it is impossible for the car to be stationary with the engine idling unless the gear is in the neutral position. An automatic transmission, however, can be in the drive position with the engine ticking over and any tendency of the vehicle to creen forward counteracted by the apolication of the handbrake. If the engine speed is then increased by depressing the accelerator pedal in normal driving, or moving the throttle controls under the bonnet, the automatic transmission engages and the car surges forward easily overcoming the handbrake. Anyone leaning over the front of the car is either run down or crushed into whatever lies ahead. The consequences as described in the four case reports can be serious. Although this cause of severe injury is uncommon it should be preventable by an awareness of its possibility.

An automatic transmission should not be in the drive position while under-bonnet adjustments are being made with the engine running. It is suggested that an appropriate warning be included in the driver's handbook.

I wish to thank Mr. D. M. Brooks, Mr. E. O'G. Kirwan, Mr. E. L. Trickev, and Mr. J. N. Wilson for allowing me to report details of patients who were under their care.

\section{MEDICAL MEMORANDA}

\section{Apparent Penicillin-induced Arrest of Mature Bone Marrow Elements}

\section{BAHMAN JOORABCHI, ELFRIEDE KOHOUT}

British Medical fournal, 1973, 2, 26-27

We report here a case in which the patient developed pancytopenia after receiving large doses of penicillin. The pancytopenia seemed to be due to a blockade of the release of mature cells from the bone marrow-a process that might be termed "postmaturation arrest." This is the first time that such a hypothesis for the cause of the anaemia in these circumstances has been advanced.

\section{Case Report}

A 12-year-old boy was admitted to hospital in severe congestive heart failure due to rheumatic carditis. Cell-block preparations and smears

Pahlavi University School of Medicine, Shiraz, Iran

BAHMAN JOORABCHI, M.D., Lecturer in Paediatrics

ELFRIEDE KOHOUT, M.D., M.R.C. PATH., Lecturer in Pathology of bone marrow showed hypercellularity with pronounced erythroid hyperplasia. The myeloid differential count was normal. One injection of benzathine penicillin, digoxin, mercurial diuretics, and iron were prescribed. He had not previously received penicillin. By the end of the third week there was no fever and the haemoglobin had risen to $11 \mathrm{~g} / 100 \mathrm{ml}$.

On day 43 the patient developed fleeting hypertension, facial puffiness, microscopic haematuria, and mild proteinuria. Five days later he suddenly developed severe headache, meningismus, and a lowgrade fever. On a provisional diagnosis of bacterial endocarditis, treatment with crystalline penicillin 20 megaunits $/ 24 \mathrm{hr}$ intravenously and streptomycin $600 \mathrm{mg} / 24 \mathrm{hr}$ intramuscularly was begun. The meningeal signs and the fever disappeared in $\mathbf{4 8}$ hours and his general condition improved. After 10 days of penicillin therapy the $\mathrm{Hb}$ was $7.2 \mathrm{~g} / 100 \mathrm{ml}$ and the total white cells $8,200 / \mathrm{mm}^{3}$, with 5,000 neutrophils $(61 \%)$ and 246 eosinophils (3\%). Both direct and indirect Coombs tests were negative and remained so on four other occasions over the ensuing two weeks. On the 13th, 17th, and 22nd days of penicillin therapy (streptomycin was discontinued after 14 days) whole-blood transfusions of $250 \mathrm{ml}$ were given. These raised the $\mathrm{Hb}$ to $11.8 \mathrm{~g} / 100 \mathrm{ml}$. On the 18th day a nonpruritic papular rash appeared on the trunk. The white cell count was $3,300 / \mathrm{mm}^{3}$, with 660 neutrophils $(20 \%)$ and no eosinophils. The total number of lymphocytes was relatively unchanged and there were no atypical forms. The platelet count was $80,000 / \mathrm{mm}^{3}$ and the reticulocytes $0 \cdot 2 \%$. The skin rash gradually became purpuric and there was one episode of epistaxis. Repeated tests for the presence of antipenicillin antibodies were negative. Immunoelectrophoresis showed, not unexpectedly, raised IgG. 